\title{
Resenha
}

DAWSEY, John; MÜLLER, Regina; MONTEIRO, Mariana [et al.] (org.). Antropologia e performance: ensaios Napedra. São Paulo: Terceiro Nome, 2013. 499 pp.

\section{A performance em diálogo}

\author{
Luciane Moreau Coccaro \\ Universidade Federal do Rio de Janeiro, Rio de Janeiro, RJ, Brasil \\ lu.coccaro@gmail.com
}

Essa coletânea, uma realização do Napedra - Núcleo de Antropologia, Performance e Drama da USP, é resultado de pesquisas desenvolvidas no Projeto Temático "Antropologia da performance: drama, estética e ritual". Tanto o projeto quanto a publicação foram financiados pela Fundação de Amparo à Pesquisa do Estado de São Paulo/Fapesp. Um dos méritos desse livro foi tornar públicas reflexôes sobre performance, no diálogo entre antropologia e artes cênicas. Ambas as áreas se entrelaçam em discussões aprofundadas nos artigos, o que faz a coletânea se distanciar de meras publicaçóes de professores e seus orientandos apenas para pontuar na Capes. Devido ao encontro sistemático de pesquisadores oriundos de diferentes universidades e/ou variados núcleos de pesquisa em âmbito acadêmico e artístico, o livro nos fornece um panorama atualizado de estudos da performance no Brasil. $\mathrm{O}$ que torna o Napedra um núcleo referência de pesquisa na área, nas vertentes de Turner e Schechner. No desejo de promover um ponto de contato interdisciplinar entre as artes da performance e a antropologia, o livro vem com um CD com sete vídeos - cada um desses autores realizou uma composição audiovisual relacionada a sua pesquisa.

A coletânea foi organizada a quatro mãos. Encabeçando o projeto está John Dawsey, professor titular do Departamento de Antropologia da USP, coordenador do Napedra e uma das referências nos estudos da performance no Brasil há pelo menos dez 
anos. A professora Regina Müller é coordenadora associada do Napedra, antropóloga e atriz, atualmente é livre-docente em Antropologia da Dança pela Universidade Estadual de Campinas e professora aposentada do departamento de Artes Corporais do IA /Unicamp. Rose Hikiji é professora do Departamento de Antropologia da USP e coordenadora do PAM - Pesquisa em Antropologia Musical e vice-coordenadora do Gravi - Grupo de Antropologia Visual, que realiza e dá suporte às sete produçóes audiovisuais que fazem parte do livro. E, Mariana Monteiro, professora de Artes Cênicas no Instituto de Artes da Unesp e diretora de teatro.

A proposta de interdisciplinaridade do Napedra tem dois méritos. Por um lado, os organizadores articulam o intercâmbio entre pesquisadores de 17 instituiçôes de Ensino Superior. Por outro lado, essa interlocução se dá em diversas áreas: antropologia, artes cênicas, história da arte, cinema entre outras. Essa diversidade de temas sobre performance e as maneiras de abordá-la é o que iremos encontrar ao longo dos artigos do livro, que traz também trabalhos de alunos de pós-graduação e de performers.

No Brasil, o Napedra tem sido responsável por promover esse intercâmbio entre pesquisadores através de eventos na USP. Em 2010, o núcleo organizou o Encontro Nacional de Antropologia e Performance e, em 2011, realizou o EIAP Encontro Internacional de Antropologia e Performance. Em diálogo com o Napedra há dois outros polos de investigação que merecem destaque, o grupo Gesto - Grupo de Estudos em Oralidade e Performance - sob a coordenação de Jean Langdon na UFSC e o Transe - Núcleo Transdisciplinar de Estudos sobre a Performance da UNB, coordenado por João Gabriel Teixeira. O Gesto tem desenvolvido desde 2005 intercâmbios entre antropólogos e artistas, ademais de publicaçôes na área desde 1995 através do periódico Antropologia em primeira mão. Em 2011 a Revista Ilha do Ppgas da UFSC publicou um "Dossiê Antropologia em Performance”, fruto de dois colóquios na área sob liderança de Vânia Zikán Cardoso. A coletânea objeto dessa resenha, vem dar continuidade aos diálogos entre pesquisadores de distintas instituiçóes.

A escolha do título Antropologia e performance dá pistas da amplitude e variedade de diferentes perspectivas de estudos da performance encontradas nos artigos do livro, seguindo a proposta dos organizadores da coletânea de dizer não ao enclausuramento do uso do termo performance a uma área de conhecimento restrita ou a uma definição única. Performance pode ser tanto objeto de análise antropológica, quanto uma epistemologia que 
nos permite interpretar algum evento como performance. Como sugere Diana Taylor no Prefácio "os ensaios nesta coletânea exploram um amplo espectro de modalidades da performance atravessando disciplinas acadêmicas e artísticas" (: 9). Por outro lado, o subtítulo ensaios Napedra nos remete aos treinamentos que atores e bailarinos fazem por meio de experimentaçóes, repetiçóes, acertos e erros nas preparaçóes de seus espetáculos. Ensaio como a tradução da palavra rehearsal contém a ideia de processo presente na maioria dos textos que relatam experiências oriundas de pesquisas de campo. Ensaio significando o gênero literário há apenas o de Dawsey.

O livro apresenta 28 artigos reunidos em 5 partes: três textos de apresentação da coletânea, que constituem uma parte fundamental para situar o debate dos demais artigos num eixo comum de entendimento sobre as relaçôes entre as artes da performance e a antropologia, ademais de estabelecer parâmetros para a leitura da coletânea.

A primeira parte é composta pelo Prefácio escrito por Diana Taylor que introduz o tema da indeterminação e variação do uso do termo performance na área da antropologia, o que coloca o debate sobre performance para cada antropólogo como autodesafio. $\mathrm{Na}$ abertura da coletânea há também um artigo de Schechner, revisão do que foi publicado em 2013 na Revista de Antropologia, e uma Apresentação escrita pelos quatro organizadores que serve como chave de leitura dos capítulos do livro. Embora os artigos tenham formas diversas de abordar a performance, houve um fio condutor na divisão dos capítulos seguindo a ideia de trança de Schechner, as performances combinariam elementos de drama social com drama estético e drama ritual.

A performance vista como uma possibilidade de trançar dramas estéticos, rituais e sociais foi o enquadre dado pelos organizadores dessa coletânea frente às distintas maneiras de pensar a performance. Essa perspectiva já fora antecipada pela pesquisa de Jean Langdon e Luciana Hartmann, que em 2005 com o apoio do CNPq pesquisaram sobre as diferentes abordagens teórico-metodológicas sobre a noção de performance em estudos de antropólogos brasileiros. Elas chegaram à conclusão de que Victor Turner e Richard Schechner, assim como Stanley Tambiah, Walter Benjamin e John Austin são os mais estudados no país (Langdon, 2007).

A coletânea Antropologia e Performance fornece dados mais recentes sobre os usos da performance no Brasil. Os 25 textos estão divididos em 4 partes. A primeira - Corpo, drama e memória - reúne 6 artigos com foco em dramas sociais e cotidianos. São seis 
assuntos diferentes e todos frutos de etnografias. A segunda parte - Festa e ritual apresenta 5 artigos com o tema de performances festivas. A terceira - Filme e narrativa traz 7 textos centrados na performance no trabalho de campo. Os artigos deste bloco trazem uma discussão sobre a performance como atuação ou não atuação, relação entre atores e não atores. Os filmes são instrumentos de pesquisas antropológicas e logo emerge a questão se os antropólogos também não construiriam personagens. Essa pergunta é central na pesquisa de Francirosy Ferreira. Jean Rouch inspira a pesquisa de Rose Hikiji a partir da ideia de antropologia compartilhada. Há um jogo de papéis entre antropólogo e cineasta presente nos vídeos e textos deste capítulo. A parte IV - Antropologia e artes da performance - conta com 7 artigos com o foco em processos de criação artística contemporânea.

A publicação vem com um CD que contém 7 experiências audiovisuais resultado de estudos etnográficos e/ou criaçóes artísticas. O Napedra tem muitos méritos em investir nas pesquisas na interface entre o teatro e a antropologia, e na aposta em buscar colaboração para realização de vídeos de alguns dos trabalhos de seus pesquisadores. A diversidade nas formações profissionais dos autores mostra a congruência entre o projeto de interdisciplinaridade nas discussóes de pesquisas em performance e o resultado efetivo registrado na parte escrita da coletânea. Dos 4 organizadores, duas pesquisadoras compuseram filmes sobre suas investigações que foram eficazes e têm relevância para estar no DVD junto à coletânea. Ao analisar se haveria adequação entre o que estava proposto nos sete artigos em relação aos audiovisuais e performances produzidas por eles, percebi que nem todos conseguiram ter uma comunicação performática eficaz através do audiovisual.

As produçóes audiovisuais ofereceram resultados desiguais, percebidos na relaçáo entre concepçóes artísticas e proposta antropológica. A questão desafiadora é pensar em qual seria a melhor maneira de apresentar num suporte visual, um produto que dê conta da pesquisa numa abordagem antropológica em torno da performance. Destaco as experiências que considero eficazes como produtos artísticos e plenamente de acordo com o que era prometido no artigo: Mira, Chica... de Regina Müller é um filme de ficção criativo e artístico. As edições são muito bem feitas, mas ressalto que atrás da edição tem o domínio do lugar olhado e o sentido das coisas (Barthes e Dawsey: 19). O vídeo é um exemplo da relação entre teatro e antropologia acontecendo em performance, o que reforça a proposta da coletânea e do Napedra de encontrar afinidades entre o teatro e a antropologia, uma vez 
que ambos causam estranhamento porque provocam um deslocamento de como olhar para a performance. Ademais, a experiência de assistir o audiovisual superou as expectativas da leitura do artigo, que já eram bem boas. A arte e a rua, dirigido por Rose Hikiji e Carolina Caffé, constitui-se de fato numa experiência de compartilhamento e alteridade, pois é realizado conjuntamente com os artistas e pesquisadores moradores da comunidade que retrata. O texto explicita de forma clara as intençóes do vídeo, e este emociona porque presentifica um pouco do cotidiano dos artistas da Cidade Tiradentes, na periferia de São Paulo.

A mesma densidade e em pouquíssimo tempo de filme - pois se trata de um clip tem o vídeo Pesquisadoras Performers de Francirosy Ferreira. Trata das peculiaridades e desafios de pesquisadoras não muçulmanas entrevistando mulheres muçulmanas. Foi eficaz como uma antropologia da antropologia, coerente com a proposta escrita. O clip instiga a vontade de ler a tese e de conhecer as pesquisadoras entrevistadas. Os filmes etnográficos Tribo planetária e Ritual de vida, de Carolina Abreu e Edgar Teodoro da Cunha, respectivamente, são filmes impecáveis, mas dentro do esperado para filmes etnográficos, pois nos fazem estar dentro da pesquisa de campo.

A batalha das heroinas de Luciana Lyra e Amores de circo de Ana Lúcia Ferraz são filmes dirigidos por duas atrizes e diretoras teatrais. No primeiro vídeo, as guerreiras heroinas entrevistadas na pesquisa de campo foram gravadas durante suas performances cotidianas, e ofereceriam poética suficiente para sustentar o vídeo, mas a escolha de Luciana Lyra foi sobrepor essas imagens às de um espetáculo de dança/teatro especialmente criado sobre o tema. O mérito de Lyra foi colocar algumas das entrevistadas para atuar sua história de vida junto com atrizes/bailarinas, ainda que o processo desse encontro da arte com a antropologia não seja explicitado nem no artigo e nem no vídeo. Em Amores de circo a proposta do texto é colocada em ação através do vídeo, os artistas circenses dramatizam seus conflitos cotidianos. Nos 7 vídeos, de distintas maneiras, aconteceu a "antropologia em performance" (: 35).

A importância dessa publicação reside na louvável revisão bibliográfica feita por Taylor no prefácio, pela apresentação redigida pelos organizadores e por Schechner, no artigo inicial da coletânea, e na diversidade de artigos que compóem o livro. Essa revisão em torno do termo performance e de seus usos aplicados em pesquisas recentes, insere os leitores no debate atual sobre esse campo de estudo. A diversidade de temas e variaçóes de 
abordagens nesses usos proporciona um panorama do estado da arte desse campo específico. Além de servir de inspiração para mais trabalhos na área, sobretudo, porque assim como postulam os organizadores, a coletânea mostra que os estudos da performance no Brasil estão em expansão nos dois sentidos, na quantidade e na diversidade. $\mathrm{O}$ caráter inovador do núcleo de pesquisa Napedra se encontra na aposta interdisciplinar, enquanto muitos programas de antropologia pretendem, mas ficam apenas na pretensão. A coletânea é uma evidência deste diálogo interdisciplinar em dois níveis: entre universidades e nichos universitários distintos, e entre a antropologia da performance e os artistas performáticos, o que incentiva a entrada na universidade de artistas pesquisadores através do campo de estudos da performance. Este encontro está tanto firmado nos artigos, fruto de questionamentos em três áreas, antropologia, artes visuais e performance; quanto mostrado nos vídeos compostos para o $\mathrm{CD}$, que nos dão a dimensão mais concreta desses textos. Nada melhor que ler acompanhando a experiência da performance.

\section{Referências bibliográficas}

LANGDON, Esther Jean

2007 "Performance e sua diversidade como paradigma analítico: a contribuição da abordagem de Bauman e Briggs". Antropologia em primeira mão. Santa Catarina, UFSC, pp. 5-26. 